\title{
Educação Física, Ciência e Saúde: formação e atuação de profesores
}

Physical Education, Science and Health: teachers training and performance

Luciana Santos Collier

Universidade Federal Fluminense, Brasil

lucianacollier@gmail.com

\section{Resumo:}

A história do desenvolvimento da Educação Física enquanto campo de conhecimento é marcada por polêmicas e divergências conceituais, epistemológicas e filosóficas, que podem ser percebidas tanto nas pesquisas produzidas, como na atuação dos professores nos diferentes contextos profissionais. Este artigo tem o objetivo de, a partir da base legal que rege a atuação do professor de Educação Física na área da saúde no Brasil, aprofundar o debate sobre a formação inicial deste profissional, problematizando as ideias hegemônicas da relação entre Educação Física, Ciências e Saúde. Nossas reflexões nos dão subsídios para defender uma formação única, que contemple as abordagens das Ciências Naturais em harmonia com as abordagens das Ciências Humanas. Além disso, consideramos que as intervenções profissionais e os estudos em Educação Física, devam estar pautados numa visão mais humanizada, independentemente do contexto educativo, formal ou não formal. O conhecimento de que trata a Educação Física deve ser o mesmo em todos os campos de atuação: o movimento humano em toda a sua complexidade.

Palavras-chave: Formação de professores, Ciências humanas, Ciências naturais, Saúde.

\section{Abstract:}

The history of the development of Physical Education as a field of knowledge is marked by controversies and conceptual, epistemological and philosophical divergences, which can be perceived both in the research produced and in the performance of teachers in different professional contexts. This article aims, from the legal basis that governs the performance of the Physical Education teacher in the health area in Brazil, to deepen the debate about the initial formation of this professional, problematizing the hegemonic ideas of the relationship between Physical Education, Science and Health. Our reflections give us insights to advocate a unique formation that addresses natural science approaches in harmony with the humanities approaches. In addition, we consider that professional interventions and studies in Physical Education should be based on a more humanized view, regardless of the educational context, formal or non-formal. The knowledge that Physical Education deals with must be the same in all fields: the human movement in all its complexity.

KEYWORDS: Teacher education, Humanities, Natural sciences, Health.

\section{INTRODUÇÃO}

Para iniciarmos este debate, faz-se necessário contextualizar a discussão sobre o campo de conhecimento e pesquisa em Educação Física (EF) no Brasil, problematizando as ideias hegemônicas sobre a sua relação com as Ciências e a Saúde. Defendemos neste artigo, que as ciências que estudam a saúde, não podem tratar exclusivamente do seu caráter biológico. Seus estudos necessitam incorporar outras áreas do conhecimento sociologia, filosofia, antropologia - que contribuem para uma compreensão do complexo fenômeno da vida e da saúde.

De acordo com Manoel \& Carvalho (2011), a EF, como campo de conhecimento é relativamente jovem e as dificuldades para sua afirmação passam pela discussão acerca do seu objeto de estudo; suas afinidades com as ciências naturais e/ou com as ciências humanas e sociais; sua legitimidade no âmbito acadêmico-científico; seu reconhecimento como ciência ou como prática social e seu papel no ensino superior.

A história do desenvolvimento da EF enquanto campo de conhecimento é marcada por polêmicas e divergências conceituais, epistemológicas e filosóficas, que podem ser percebidas tanto nas pesquisas 
produzidas, como na atuação dos professores nos diferentes contextos profissionais. Segundo Velozo (2010) ao contrário de outros campos do saber, que empregam como base para suas pesquisas e intervenções as teorias e os métodos ou das ciências naturais ou das ciências humanas, na EF não existe um horizonte único ou padrão a ser seguido.

Carmo Júnior (1998) observa que a natureza da EF difere um pouco das demais ciências, sua conduta científica de pesquisa tem orientação teórico-prática (ou prático-teórica), cujos resultados são direcionados às intervenções diretas na realidade. Acrescenta que o conteúdo da EF é universal, portanto, um conceito particular de ciência não consegue atingir uma evidência rigorosa sobre a experiência em EF. $\mathrm{O}$ autor referenda que a EF deve ser pesquisada com a aplicação de princípios que escapam ao método tradicional. A observação assídua das intervenções pedagógicas (no contexto formal ou não formal) para recolher os fatos; a reflexão profunda para combiná-los e a experiência rigorosa para verificar os resultados das combinações. "A prática da pesquisa em Educação Física não deveria ser diferente da prática que fazemos com a Educação Física (grifo do autor) (p.46)".

De acordo com Velozo (2010), a EF é caracterizada por ser um campo de conhecimento multi ou interdisciplinar, cujo estudo e pesquisa têm fins de intervenção pedagógica, articulando as teorias e os métodos de várias outras ciências que podem ser chamadas de 'disciplinas-mãe'. Aprofundando a discussão, Bracht (2000) afirma que a multidisciplinaridade no campo da EF desencadeou um processo de (super) especialização e instalou um 'diálogo de surdos'. Além das subáreas não dialogarem, parece haver uma relação de hegemonia entre elas, que prioriza os conhecimentos produzidos na ótica das ciências naturais em detrimento daqueles produzidos através das ciências humanas.

Apesar de não ser uma ciência básica, Velozo (2010) adverte que definir a EF como ciência aplicada, poderia "repercutir em um entendimento demasiado pragmático da área, sob o risco de julgá-la como um campo de aplicação de saberes com finalidade meramente técnica ou tecnológica (p.81/82)”. Defende então, que o recorte que a $\mathrm{EF}$ faz, ao vislumbrar sua intervenção pedagógica, lhe confere a autonomia enquanto campo de pesquisa e produção de conhecimento.

Caparroz \& Bracht (2007) encorajam os docentes, que estão atuando nos diferentes contextos pedagógicos, a buscarem compreender e construir sua autoria como pesquisadores, baseados no processo contínuo de ação-reflexão-ação no cotidiano da prática. Esta autoria vincula-se a um exercício incessante de reflexão sobre o desenvolvimento da prática pedagógica e implica/demanda um processo de investigação e escrita. Indo mais além, os autores afirmam que o professor deve agir de forma autônoma e crítica como sujeito e autor de sua pesquisa e prática pedagógica. Complementando estas considerações, Carmo Júnior (1998) não nos deixa esquecer a essência da pesquisa em EF, quando afirma que, nesse emaranhado de conceitos, estamos pesquisando a natureza dos fenômenos e deixando de lado a natureza do humano.

Bracht (2000) destaca o fascínio que a visão científica da EF exerce sobre a comunidade acadêmica. Seu argumento é de que, ao assumir a retórica da ciência, a EF adota um modo hegemônico de fazer ciência (estritamente falando da ciência natural) e distancia-se da pesquisa e da prática pedagógica. Com relação à pesquisa na e sobre a EF escolar, Oliveira, Gomes \& Bracht (2015) afirmam que o professor-pesquisador não goza de reconhecimento, nem da sociedade, nem da comunidade acadêmica. Caparroz \& Bracht (2007) afirmam que a 'onda' cientificista provocou uma desvalorização da discussão pedagógica. As questões do cotidiano escolar perderam prestígio, reforçando a dicotomia, entre os 'teóricos' e os 'práticos'. Betti (2005) acrescenta que os professores de Educação Física escolar, passaram a não se reconhecer nos conhecimentos produzidos pelos pesquisadores da área.

Em seu estudo Manoel \& Carvalho (2011) afirmam que, no Brasil, os docentes que desenvolvem pesquisas nas subáreas socioculturais e pedagógicas perderam espaço nos programas de pós-graduação. Suas produções científicas são desqualificadas e, consequentemente, enfrentam pressões das gestões e de órgãos de fomento que privilegiam e investem em pesquisa baseada em um modelo hegemônico de ciência. Há um abismo crescente entre as prioridades das universidades e os dilemas da sociedade que caracterizam a necessidade 
de informação, conhecimento e intervenção responsáveis e adequados (p.401). Betti, Carvalho, Daolio \& Pires (2004) reforçam que o sistema de avaliação da pós-graduação, é um dos grandes vilóes desse processo de exclusão gradual a que os docentes das subáreas pedagógicas e socioculturais têm sido submetidos. Em busca de apoio financeiro, os pesquisadores da EF privilegiam o desenvolvimento de estudos voltados para a área da saúde, priorizando o enfoque biológico, no qual se concentra a maior parte das pesquisas da área.

De acordo com Velozo (2010), a fragmentação do conhecimento, portanto, se acentua nos cursos de pós-graduação em $\mathrm{EF}$, em virtude da maior valorização - financeira e acadêmica - das pesquisas com enfoque biológico em detrimento das que tem enfoque humano. Apesar de compreender a necessidade da fragmentação e especialização do saber, para o estudo e para a pesquisa, no caso da intervenção pedagógica é importante que se faça um esforço de síntese (p.91).

Apesar disso, a ideia que é disseminada sobre a EF, está relacionada às Biociências e à Saúde e se restringe ao enfoque biológico, através da fisiologia, biomecânica, bioquímica, anatomia, etc. Fazer com que a sociedade compreenda as Biociências, enquanto ciências que estudam a vida em toda a sua plenitude e a saúde de forma ampliada é uma necessidade e um desafio para pesquisadores que militam nesta área. Defendemos que a vida não se restringe ao aspecto biológico e estudar as ciências da vida (biociências) e da saúde compreende estudar, também e fundamentalmente, as ciências humanas que tratam da evolução histórica do homem, das suas relações sociais, suas ideologias, etc.

Este artigo pretende, a partir da base legal que respalda a atuação do professor de EF na área da saúde, aprofundar o debate sobre a formação inicial deste profissional, problematizando as ideias hegemônicas da relação entre EF, Ciências e Saúde.

\section{Metodologia}

Gonzaga (2006) acredita que a pesquisa qualitativa é a melhor opção quando investigamos situações, eventos e interações observáveis, além disso, acrescenta que sua diversidade metodológica, nos permite extrair dados da realidade para serem contrastados sob a luz do método. Portanto, este artigo foi desenvolvido mediante a abordagem qualitativa, de forma que fosse possível realizar uma descrição complexa do processo de formação dos professores de EF, que envolve situações dinâmicas e experiências vividas por diferentes grupos que têm particularidades de comportamentos e atitudes. Fontoura (2011) ressalta a importância da pesquisa qualitativa como processo de busca da transformação social, na medida em que ela rompe com os modelos hegemônicos de fazer ciência e nos permite "apostar na nossa própria forma de fazer e relatar pesquisas que tragam alternativas viáveis e coerentes” (p.3).

Os documentos são registros escritos que proporcionam a elucidação de fatos e relações, possibilitando a compreensão do período histórico e social das ações, pois se constituem em manifestações registradas de aspectos da vida social de determinado grupo (Oliveira, 2007). O uso de documentos em pesquisa é justificado pela riqueza de informações que deles podemos extrair e resgatar. Possibilita também ampliar o entendimento de objetos, cuja compreensão necessita de contextualização histórica e sociocultural (Cellard, 2008). Neste sentido, partimos da pesquisa documental sobre a legislação que fornece a base legal para a atuação do professor de Educação Física na área da saúde e buscamos dialogar com o referencial teórico escolhido. Desta forma, elucidamos os contextos, problematizamos as ideias hegemônicas, buscamos novos fatos e apontamos observações necessárias ao estudo, organizando e interpretando todas as informações extraídas dos documentos, segundo os objetivos da investigação proposta (Pimentel, 2001).

$\mathrm{Na}$ análise documental foram apreciadas as Diretrizes Curriculares Nacionais (DCNs), e as resoluções do Conselho Nacional de Educação (CNE) que servem de eixo condutor e explicitam a proposta de formação do professor de Educação Física para atuar no contexto da Saúde Pública. Neste sentido, foram incluídos também os documentos reguladores do PRÓ-SAÚDE, a fim de elucidar de que maneira este programa pode colaborar na formação destes professores. Por último, analisamos também o manifesto da Associação 
Brasileira de Ensino da Educação Física para a Saúde (ABENEFS) que, por não ser um documento oficial, foi analisado na seção que trata da formação profissional e não junto com a base legal regulamentadora da profissão. A coleta e análise destes documentos foi feita no período compreendido entre abril de $2012 \mathrm{e}$ fevereiro de 2016 fazendo parte de uma tese de doutorado em Ensino em Biociências e Saúde, no Instituto Oswaldo Cruz (FIOCRUZ).

\section{Resultados e discussão}

\section{Base Legal da Educação Física na Saúde}

A análise dos documentos que constituem a base legal para a atuação do professor de Educação Física na área da saúde, possibilita a compreensão do processo de formação do professor de EF, tendo em vista as competências e habilidades exigidas para a sua atuação na área da Saúde Pública. Este corpo de documentos é composto por resoluções e pareceres do Ministério da Saúde e da Educação que, além de normatizarem, orientam os princípios e objetivos desta atuação.

Com o aumento e modificação da demanda por saúde ao longo do século passado, surgiu a necessidade de incluir novas áreas do conhecimento no debate e intervenção na saúde. Para Faria Junior (2001) a lei $n^{\circ} 9.696$ de 1 de setembro de 1998, que dispõe sobre a regulamentação da Profissão de EF e cria os respectivos Conselho Federal e Conselhos Regionais de EF, baseou-se em um projeto desatualizado teoricamente, que manteve relações de hegemonia, inspirado em modelos de outras profissões liberais e, portanto, fundamentado em 'ideias funcionalistas da profissão' (p. 28). Apesar disso, a inserção da EF no campo de atuação profissional da Saúde Pública ocorreu em 1998 com a Resolução no 287, de 8/10/98 do Conselho Nacional de Saúde, quando passou a ser considerada como profissão da área da Saúde (Brasil, 1998).

Somente dez anos depois, a portaria n ${ }^{\circ}$ 154, de 24 de janeiro de 2008 do Ministério da Saúde, publicada no D.O.U. no 43, de 04/03/2008, Seção 1, fls. 38 a 42, cria os Núcleos de Apoio à Saúde da Família NASF (Brasil, 2008), incluindo os professores de EF no rol de profissionais que o compóe. Neste momento o professor de EF passa a ter um setor específico para atuar em Saúde Pública. O NASF tem o objetivo de apoiar a consolidação da Atenção Básica no Brasil, ampliando sua abrangência e resolubilidade. São equipes multiprofissionais que devem trabalhar de forma integrada às equipes Saúde da Família, apoiandoas e compartilhando saberes.

A Portaria 154/2008 do Ministério da Saúde, criou o NASF 1 e 2 com respectivamente um mínimo de 5 e 3 profissionais de diferentes ocupações do Código Brasileiro de Ocupações ( $\mathrm{CBO}$ ) e determina que suas equipes multidisciplinares devem ser compostas por Médico Acupunturista; Assistente Social; Profissional/ Professor de EF; Farmacêutico; Fisioterapeuta; Fonoaudiólogo; Médico Ginecologista; Médico Homeopata; Nutricionista; Médico Pediatra; Psicólogo; Médico Psiquiatra; e Terapeuta Ocupacional.

A Portaria 2.488/2011 do Ministério da Saúde (Brasil, 2012), dentre outras providências, redefine as categorias profissionais participantes dos NASF 1 e 2, passando então a compor essas equipes as seguintes ocupações do CBO: Médico Acupunturista; Assistente Social; Profissional/Professor de EF; Farmacêutico; Fisioterapeuta; Fonoaudiólogo; Médico Ginecologista/Obstetra; Médico Homeopata; Nutricionista; Médico Pediatra; Psicólogo; Médico Psiquiatra; Terapeuta Ocupacional; Médico Geriatra; Médico Internista (clínica médica), Médico do Trabalho, Médico Veterinário, profissional com formação em arte e educação (arte educador) e profissional de saúde sanitarista, ou seja, profissional graduado na área de saúde com pós-graduação em Saúde Pública ou coletiva ou graduado diretamente em uma dessas áreas. 
A Portaria 3124/2012 do Ministério da Saúde (Brasil, 2012), cria o NASF 3 abrindo a possibilidade de qualquer município do Brasil tenha uma equipe do NASF, desde que tenha ao menos uma equipe de Saúde da Família.

Do ponto de vista da formação profissional a grande modificação ocorre com as reformas educacionais realizadas no Brasil a partir do final da década de 90 , quando se iniciam as discussões sobre a elaboração das novas diretrizes curriculares para os cursos de graduação, levando alunos, professores e funcionários das instituições de ensino superior a debaterem, em maior ou menor medida, as mudanças contidas nestas diretrizes.

Para os cursos da área de saúde, as diretrizes curriculares homologadas em sua maioria, nos anos de 2001 e 2002 são resultantes da disputa entre diferentes ideologias, especialmente entre as daqueles que defendiam o desenvolvimento das disciplinas em ambientes hospitalares e intramuros das universidades e as concepções daqueles que, assim como indicavam as novas diretrizes, defendiam uma formação voltada para o campo da Atenção Primária à Saúde (Rossoni \& Lampert, 2004).

Assim, a partir das mudanças propostas para os currículos dos cursos das áreas da saúde, impôs-se às instituições de ensino superior, o desafio de uma formação generalista, humanista, crítica e reflexiva em que os profissionais sejam capazes de atuar na integralidade da atenção à saúde e em equipe multiprofissional, características exigidas para atender aos princípios do Sistema Único de Saúde (SUS).

Apesar das diretrizes indicarem a atuação do professor de EF nos espaços públicos e em equipes multiprofissionais, e definirem que o egresso deve ser responsável pela prevenção, promoção, proteção e reabilitação da saúde (Brasil, 2004), Pasquim (2010) rebate, afirmando que, aparentemente, tal indicação surge apenas como reserva de mercado, buscando garantir um espaço no SUS e não impondo, a princípio, nenhuma alteração em sua intervenção ou formação profissional.

Tais determinações respaldam legalmente a atuação dos professores de EF na área de saúde, bem como determinam competências a serem desenvolvidas em seus cursos de graduação a fim de habilitá-los profissionalmente para tal atuação. Além disso, possibilitam o acolhimento das contribuições da EF, que vem se dedicando a gerar propostas pedagógicas alternativas que se comprometam com a Promoção da Saúde, e especialmente com o componente 'educação em saúde'. É importante esclarecer que, as contribuições que melhor atendem aos princípios do SUS, não decorrem das formulações hegemônicas da atividade física, voltada para a saúde, pautadas nos aspectos biológicos. Ou seja, ao pensar a promoção da saúde pelo viés da doença, a EF se limita a atuar na consequência (patologias), deixando de colaborar com a solução dos problemas da Saúde Pública, que abrangem aspectos multifatoriais.

Embora esta seja a maneira consensualmente aceita em nossa sociedade - inclusive entre os profissionais da saúde -, as estratégias pedagógicas de educação em saúde, baseadas nas abordagens críticas da EF, apresentam uma maior concordância com os princípios do SUS e podem gerar, portanto, intervenções mais consistentes e efetivas para a promoção da saúde. Segundo Alves Júnior (1992) mesmo com a concepção e emergência das teorias críticas da EF, as atitudes e práticas, enraizadas e ideologizadas de grande parte dos professores de EF permaneceram as mesmas. A associação entre atividade física, desporto e saúde com as doenças da civilização aponta para o processo de medicalização da EF (Alves Junior, 1992) que contraria frontalmente a proposta de desmedicalização do movimento de Promoção da Saúde.

Na perspectiva da elaboração de políticas públicas de Promoção da Saúde, o Ministério da Saúde, em setembro de 2005, definiu a Agenda de Compromisso pela Saúde (Brasil, 2006) que agrega três eixos: O Pacto em Defesa do SUS, O Pacto em Defesa da Vida e o Pacto de Gestão. Dentro do Pacto pela Vida, que constitui um conjunto de compromissos sanitários que deverão se tornar prioridades inequívocas dos três entes federativos, as macro prioridades foram descritas como

fortalecimento e qualificação estratégica da saúde da família; a promoção, informação e educação em saúde com ênfase na promoção de atividade física, na promoção de hábitos saudáveis de alimentação e vida, controle do tabagismo; controle do uso abusivo de bebida alcoólica; cuidados especiais voltados ao processo de envelhecimento (p.5). 
A Política Nacional de Promoção da Saúde ratificou o compromisso do Ministério da Saúde na ampliação e qualificação das ações de promoção da saúde nos serviços do SUS. Neste sentido, em 03 de novembro de 2005, foi assinado documento denominado PRÓ-SAÚDE (Programa Nacional de Reorientação da Formação Profissional em Saúde), que representa importante pacto intersetorial já consolidado entre os Ministérios da Saúde e da Educação (Brasil, 2005). Este programa prevê a educação permanente dos profissionais da área da saúde, incorporando aos seus princípios norteadores a substituição do modelo tradicional do cuidado em saúde, historicamente centrado no atendimento hospitalar e na doença, para um modelo mais humanizado com foco maior nas ações de prevenção. Desta forma, além de contribuir na formação, também promove a alocação, qualificação, valorização e democratização das relações de grupos são compostos por docentes (tutores), profissionais dos serviços (preceptores) e estudantes da graduação da área da saúde.

Em 2007, o PRÓ-SAÚDE passa a incluir em seu bojo, projetos voltados para a formação dos professores de Educação Física (Brasil, 2007). Os projetos das Instituições de Ensino Superior (IES) são aprovados pelo Governo Federal e desenvolvidos em parceria com as Secretarias de Saúde e devem incentivar a integração ensino-serviço-comunidade. Através da inserção de docentes e alunos das IES na rede pública de saúde, as necessidades dos serviços passam a ser fonte de produção de conhecimento e pesquisa.

Paralelo a este movimento, o Conselho Nacional de Educação (CNE) elaborou os documentos reguladores dos cursos de Educação Física, contemplando a intervenção dos profissionais formados por estes cursos nos serviços de Saúde Pública, considerando as demandas das políticas públicas interministeriais, que incluem estes profissionais nas equipes multidisciplinares do SUS.

Em 2004, o CNE, através da resolução n 7, de 31 de março, institui as Diretrizes Curriculares Nacionais (DCN) para cursos de bacharelado e licenciatura em EF, visando organizar, em âmbito nacional, os projetos pedagógicos de diferentes instituiçóes, com o propósito de assegurar que o aluno vivencie uma "formação generalista, humanista e crítica, qualificadora da intervenção acadêmico-profissional, fundamentada no rigor científico, na reflexão filosófica e na conduta ética" (Brasil, 2004, p.1).

$\mathrm{O}$ artigo $4^{\circ}$ do referido documento, determina que

$\$ 1^{\circ} \mathrm{O}$ graduado em Educação Física deverá estar qualificado para analisar criticamente a realidade social, para nela intervir acadêmica e profissionalmente por meio das diferentes manifestaçóes e expressões do movimento humano, visando à formação, a ampliação e o enriquecimento cultural das pessoas, para aumentar as possibilidades de adoção de um estilo de vida fisicamente ativo e saudável.

$\$ 2^{\circ} \mathrm{O}$ Professor da Educação Básica, licenciatura plena em Educação Física, deverá estar qualificado para a docência deste componente curricular na educação básica, tendo como referência a legislação própria do Conselho Nacional de Educação, bem como as orientações específicas para esta formação tratadas nesta Resolução (p. 1 e 2).

Este artigo explicita as possibilidades de intervenção, tanto para bacharéis como para licenciados, reforçando a ideia de que ambos devam estar habilitados a trabalhar no contexto da Promoção da Saúde, em seus diferentes contextos de prática. À formação do licenciado são acrescidas disciplinas que o habilita à docência, mas em seguida o parágrafo $2^{\circ}$ ratifica que estão mantidas, para esta formação, as demais orientações contidas na resolução. Neste sentido o Parecer n 274 do CNE/CES aprovado em 06/07/2011 reforça

\footnotetext{
As Diretrizes Curriculares Nacionais para os cursos de graduação em Educação Física são únicas, e qualquer outra interpretação é imprópria. Os conteúdos curriculares, assim como as competências e habilidades previstas nas Diretrizes, referentes ao campo técnico-científico da Educação Física, são idênticas para a licenciatura e o bacharelado, não havendo divisão possível para nenhum efeito. Mais uma vez, deve ser ressaltado que a licenciatura requer competências adicionais, nos termos da já citada Resolução CNE/CP nº 1/2002 (Brasil, 2011, p.6).
}

As interpretações equivocadas do texto da lei, junto com a pressão política e imposições arbitrárias do Conselho Federal de EF (CONFEF), vem acarretando consequências desastrosas para os professores de EF. A divisão da atuação profissional agrava o problema da falta de oportunidades de emprego, bem como, gera disputa entre licenciados e bacharéis. Além disso, importa-se uma nomenclatura pertinente a outros tipos de formação superior, mas que parece equivocada no contexto da EF, na medida em que qualquer 
egresso dos seus cursos realizará práticas educativas e intervenções pedagógicas. Licenciado ou bacharel, o graduado em EF será um disseminador, multiplicador e construtor do conhecimento relativo à cultura corporal. Portanto, todos serão professores e necessitarão dos conhecimentos didáticos e metodológicos que compõem as licenciaturas de todas as áreas. Na maioria das profissões, os bacharéis não estão habilitados a ministrar aulas, em qualquer que seja o contexto educativo, formal ou não formal.

Segundo Faria Júnior (2001), desde os anos 70, estimulava-se a criação de instituições de ensino superior privadas com inclusão de cursos de bacharelado, integrando a estratégia de transformar a EF numa profissão liberal. O autor argumenta também que a corrente privatista, que já lutava pela transformação da EF em uma 'profissão liberal', desde aquela época, acabou adotando a estratégia da fragmentação da profissão, que em anos anteriores recebia o nome de 'habilitação'. Freitas (2007) constatou que o modelo de formação em EF tem privilegiado o trabalho individual e o espaço privado. Em estudo realizado por Falci \& Belisário (2013) identificou-se que a tradicional inserção do professor de EF no setor privado faz com que posturas e concepções advindas desse campo sejam reproduzidas também no setor público.

Com a criação do bacharel, a questão do emprego do professor de EF passou a ser uma questão de mercado, resultante da competitividade. Os bacharéis são estimulados a procurar seus próprios caminhos como personal trainners, administradores desportivos, preparadores físicos, técnicos desportivos, promotores de eventos desportivos, consultores para empresas e clubes, e até animadores de festas infantis. São incentivados a conquistar espaços "em condomínios, em empresas e até mesmo em residências particulares, a montar e desenvolver seus próprios negócios - SPAs, Health Clubs, academias, ofertas terceirizadas, workshops considerados filões lucrativos" (Faria Junior, 2001 p. 56).

Prosseguindo com as reflexões, o autor chama atenção para o fato de que os primeiros bacharéis começaram a perceber que o mercado não tem tanto poder de expansão e de geração de empregos e que o ideal de profissional liberal está longe de ser alcançado. Restam apenas empregos em clubes e academias com salários discriminados e o sonho de ser um micro ou pequeno empresário, com seu próprio negócio, está cada vez mais longe de ser alcançado, uma vez que o neoliberalismo só favorece aqueles que dispóem de grande volume de capital (Faria Junior, 2001). O que vem ocorrendo é exatamente o que as instituições de ensino superior (IES) privadas queriam, quando apoiaram a divisão da formação. Os bacharéis estão voltando para as faculdades para complementar sua formação com a licenciatura e poder atuar nas escolas. Por sua vez, os licenciados têm sido obrigados a voltar para as faculdades para cursar o bacharelado, por serem, equivocadamente, impedidos de atuar nos diferentes contextos pedagógicos. Desta forma, as IES particulares lucram de ambos os lados, pois, dificilmente, um professor formado, já atuando no mercado de trabalho (ainda que precariamente), poderá prestar novo concurso para ingressar numa IES pública, cuja concorrência é muito acirrada. Este professor não dispõe de tempo para estudar, portanto opta por um processo seletivo simplificado, numa IES particular.

Castellani Filho (2016) argumenta que o bacharelado em EF se reduz a uma formação centrada em visão anacrônica de saúde, nada tendo a ver com o entendimento de saúde da política pública brasileira, que está apoiado em conceitos que a ressignificam a ponto de fazer com que o SUS se torne referência no cenário internacional. Para alguns autores a estruturação do curso de EF em licenciatura e bacharelado é considerada uma alternativa para melhor caracterizar o campo de intervenção de cada habilitação e melhor definir as competências e saberes de cada eixo (Nunes, Votre \& Santos, 2012; Souza \& Loch, 2011). Contudo, no estudo de Falci \& Belisário (2013) os entrevistados apontaram que esta separação fez com que o bacharel perdesse a essência humanista, prejudicando sua atuação, sobretudo no que concerne ao cuidado integral. Brugnerotto \& Simões (2009) endossam esta afirmação, ao observarem que o enfoque humanista da saúde, quando abordado, ocorre nos cursos de licenciatura. Pasquim (2010) corrobora ao afirmar que a separação dos cursos de EF desfavorece a prática integral do professor de EF.

Com base nos documentos apresentados acima, podemos afirmar que apesar da ampliação legal no horizonte profissional da EF, as iniciativas até aqui implementadas ainda não foram suficientes para promover 
uma efetiva atuação na área da Saúde Pública (Bagrichevisky \& Estevão, 2008). O cenário de inclusão do professor de EF área da saúde ainda precisa ser melhor discutido e valorizado. O reconhecimento legal não foi suficiente para sustentar a atuação dos professores de EF na Saúde Pública e a formação ainda apresenta lacunas que impedem a elaboração de ações mais consistentes de intervenção (Pasquim, 2010; Falci \& Belisário, 2013).

\section{Educação física e saúde}

De acordo com Silva et al. (2013), desde a metade do século XX, as pesquisas da área de Educação Física passaram a descrever a importância da atividade física para a prevenção de agravos não transmissíveis saúde e os problemas decorrentes da inatividade física. Neste enfoque o termo EF é substituído por atividade física/ exercício físico e a saúde é traduzida em prevenção de doenças.

Hallal \& Knuth (2011) explicam que

O caminho científico de produção de conhecimento na área de atividade física relacionada com a saúde acabou se hospedando em centros de epidemiologia e saúde coletiva, as pesquisas desse campo acabam tendo um componente quantitativo bastante robusto. Por outro lado, a aproximação da pesquisa quantitativa com outras abordagens metodológicas parece ser um caminho ainda pouco explorado, porém promissor, principalmente se vincularmos essa produção ao campo da Educação Física e suas subáreas distintas, as quais claramente precisam estar mais conectadas (p.183).

É necessário compreender a saúde e a atividade física como fatos sociais, que possuem natureza complexa e multideterminada que necessitam ser estudados de forma multidisciplinar e através de distintas abordagens. A compreensão do 'lado biológico' do ser humano não é suficiente para conhecê-lo. Velozo (2010) acrescenta que é necessário ter consciência dos limites da visão fragmentada da realidade. A compreensão da totalidade de um fato social, gera novas reflexões sobre a cientificidade nas ciências que se dedicam ao estudo do homem, abrindo possibilidades para a EF, que é uma área de conhecimento que estuda e atua sobre o ser humano. Continuando com Hallal \& Knuth (2011), promover a atividade física é um processo complexo. Neste sentido, o acúmulo de conhecimento científico (baseado nas investigações de cunho epidemiológico) acerca dos benefícios da atividade física, não foi suficiente, de forma isolada, para gerar aumento nos níveis populacionais de atividade física, nem mudanças comportamentais contundentes no conjunto da sociedade brasileira.

Em sua pesquisa, Luz (2007) evidenciou que os indivíduos são aconselhados a praticar atividades físicas para prevenir ou combater doenças variadas. Muitas vezes esta recomendação é feita por um médico, sob a forma de prescrição, apesar deste profissional não estar habilitado para fazê-lo. Nesta perspectiva, a atividade física é vista como um 'remédio', que o indivíduo toma quando precisa, para curar uma doença. Assim que melhora, costuma interromper o seu uso. Zimmermann (2001) explica que a atividade física está vinculada à saúde, mas não como uma pílula, cujos efeitos podem ser controlados, mas sim porque é uma forma de movimento, expressão de nossa vida, forma de comunicação com o mundo, atividade vital para nossa sobrevivência.

Conte \& Gonçalves (2001) lembram que as alterações fisiológicas promovidas pelo exercício físico, isoladamente, não são capazes de tornar as pessoas mais saudáveis. Ouriques (2006) acredita ser necessário analisar a relação atividade física-saúde sob outro ponto de vista. Para além do fascinante campo biológico das estruturas naturais, dos mecanismos, das leis invariáveis que regem o funcionamento do homem e do universo, é necessário enxergar também o social, o cultural e o histórico agindo sobre esse homem e sobre esse universo. Sobral (1991) ressalta que a associação sem reservas entre exercício físico e saúde, numa relação de causalidade, pode nos levar ao campo do 'otimismo ingênuo', uma vez que os benefícios do exercício dependem de inúmeras circunstâncias acerca de como é praticado. Segundo Ferreira (2001), a atividade física deve ser encarada como um meio potencial de contribuição positiva para a saúde, pois ao desenvolvimento da 
aptidão física não corresponde necessariamente uma melhoria do status de saúde e nem todas as repercussões do exercício físico e do desporto são benéficas à saúde. Portanto, as intervenções da EF relacionadas à saúde devem ser no sentido do empoderamento, para que os sujeitos - individual e coletivamente - sejam capazes de selecionar as atividades físicas que satisfazem suas próprias necessidades e interesses, de avaliar seus próprios níveis de aptidão física e de resolver seus próprios problemas de saúde.

\section{Educação Física e promoção da saúde}

Dentro do contexto da Promoção da Saúde, o professor de EF deve estar apto a se inserir tanto na prevenção, como na educação. No âmbito da prevenção às doenças, sua atuação deve ser no sentido de fomentar nos sujeitos a opção por estilos de vida que incluam a prática regular de atividades físicas. Entretanto, a escolha por uma vida ativa, recai na decisão individual, que deve ser crítica e consciente das opções (Alves Júnior, 1992). Por outro lado, a educação em saúde, transforma professores de EF em agentes de saúde, ultrapassando a esfera da educação escolar, para atingir também os contextos educativos não formais e informais. No âmbito das práticas educativas em saúde, ele é o profissional que pode lançar mão de importantes conhecimentos adquiridos em seu processo de formação - pedagogia, didática, metodologia do ensino - para construir ações e estratégias de ensino em saúde que possibilitem o empoderamento dos sujeitos na busca de soluções para os problemas que determinam de ser saudável e possibilitando uma maior ingerência no controle e na implementação de políticas públicas de saúde.

Nas equipes multidisciplinares de saúde, nenhum outro profissional tem como preocupação central a cultura corporal. Lembrando que quando falamos de cultura corporal, não estamos falando apenas do movimento, mas de tudo que interfere no movimento humano: aspectos biológicos, sociais, políticos, psicológicos, antropológicos, etc. Estes fatores, além de interferirem no movimento humano, se constituem importantes determinantes da saúde.

Esta propriedade em lidar com a cultura corporal, embora ainda seja vista como exclusividade do professor de EF, precisa ser compartilhada e apreendida pelos demais profissionais da saúde. A cultura corporal trata o ser humano em sua integralidade (princípio defendido pelo SUS) e só pode ser construída coletivamente, sendo, portanto, uma possibilidade pertinente ao trabalho multidisciplinar (Brasil, 2001). Scabar, Pelicioni \& Pelicioni (2012) acrescentam que é necessário buscar o amadurecimento de todos os profissionais da saúde, para que cada um siga desempenhando suas funções mas, conjuntamente, construindo e consolidando experiências, transcendendo os antagonismos e expandindo as ações a fim de implementar um modelo de atenção integral. Esta mudança de paradigma deve ser implementada na formação inicial de todos os profissionais que atuam na área da saúde, mas também deve ser fortalecida nos diferentes programas, projetos e demais iniciativas que compõem a formação continuada.

Segundo as Diretrizes do NASF, cada profissional deve comprometer-se com o trabalho por meio da sua especialidade e todos devem se comprometer com as propostas de promoção da saúde integral uma vez que é insuficiente pensar o indivíduo de forma fragmentada, por áreas de estudo no campo da saúde ou mesmo considerar que sua saúde está restrita ao adequado funcionamento dos sistemas fisiológicos (Brasil, 2009). Para Scabar et al. (2012) tais diretrizes propõem a ressignificação das práticas corporais/ atividade física (PCAF), a partir do entendimento de saúde como resultante dos determinantes e condicionantes sociais da vida, destacando como essencial o reconhecimento da promoção da saúde como resultado da dinâmica de produção de vida (p.415). Moretti, Almeida, Westphal \& Bógus (2009) acrescentam que qualquer que seja o programa de práticas corporais/ atividade física (PCAF), dentro do contexto da saúde, deve priorizar processos educativos que ultrapassem a mera transmissão de conhecimentos, favorecendo, entre outros aspectos, o enfrentamento das dificuldades e o fortalecimento da identidade dos sujeitos e das coletividades.

Pensando com Bagrichevsky \& Estevão (2008) precisamos promover a participação do professor de Educação Física na saúde sustentada pelo estímulo a uma cultura corporal criativa, para 'humanizar' a 
assistência das pessoas e não apenas por uma ação meramente tarefeira de prescrições fisiológicas (prédeterminadas pela área médica) que buscam exclusivamente evitar comportamentos de risco. Sem pretender desvalorizar o aspecto terapêutico desse tipo de intervenção, nem a validade do mesmo para o controle de muitas patologias, acreditamos nas ações da Educação Física no âmbito da saúde que possam ir além do que é proposto pelo modelo hegemônico, médico-centrado. Defendemos a formação de sujeitos autônomos, dotados de consciência crítica, capazes de avaliar, optar e realizar atividades físicas que lhe proporcionem bem estar e não corpos domesticados apenas repetidores de movimentos sem significado para a promoção da sua saúde.

Neste sentido, não nos restam dúvidas que o professor de Educação Física deve atuar nos diferentes contextos de promoção da saúde. Porém, esbarramos em um importante entrave inicial para que este panorama venha a se concretizar: a formação dos professores de Educação Física que, analisada por diversos autores, (Anjos \& Duarte, 2009; Bagrichevsky \& Estevão, 2008; Carvalho \& Ceccim, 2006; Gonçalves \& Castro, 2009; Freire, Verenguer \& Reis, 2002) ainda não conseguiu consolidar sua atuação na área da Saúde Pública. Desta forma, o professor de EF não conseguirá interferir no processo saúde-doença se sua formação e atuação forem alheias ao que diz respeito à dimensão coletiva, pública e social do mesmo (Anjos \& Duarte, 2009).

\section{Formação inicial e atuação na saúde}

Os efeitos da fragmentação do conhecimento não ficam restritos ao campo da pesquisa, mas atropelam o ensino e a formação dos futuros professores de EF, dificultando ainda mais a compreensão do complexo fenômeno da saúde. No contexto da graduação a noção dicotomizada de EF, gerou a separação da formação inicial em licenciatura e bacharelado (contexto brasileiro), obrigando o aluno a decidir por uma habilitação que lhe permita atuar ou no contexto escolar ou fora dele.

Pensando numa formação mais sólida para todos os professores de EF, Falci \& Belisário (2013) acreditam que a superação das limitações impostas pela divisão da formação inicial, "pode começar pelo estabelecimento de estratégias tais como: reestruturação curricular, maiores oportunidades de aproximação da realidade através de estágios, transversalidade do tema na grade curricular e interação com outras áreas do conhecimento através de disciplinas integradas" (p. 897).

Em estudo realizado por Anjos \& Duarte (2009), foi apontado que a formação em EF destoa da demanda imposta pelos serviços públicos de saúde, que têm como princípios doutrinários: a universalidade, que determina o acesso de todos à saúde; a equidade que objetiva diminuir desigualdades sem discriminar a universalidade e a integralidade que reconhece o ser humano como um todo e não em partes, respeitando suas necessidades biopsicossociais em todos os âmbitos do sistema de saúde (Brasil, 2001). Enquanto isso, a formação em EF voltada para a saúde se preocupa prioritariamente com os componentes biológicos e epidemiológicos da saúde e acrescentando em sua grade curricular disciplinas voltadas para a compreensão da doença, não da saúde.

Ao longo do ano de 2015 a Associação Brasileira de Ensino da Educação Física para a Saúde (ABENEFS) organizou uma série de encontros de professores de EF e publicou o Manifesto da ABENEFS. O objetivo deste documento foi de contribuir com sugestões para que os cursos superiores de EF - seus docentes, coordenadores e profissionais dos serviços de saúde - possam ampliar e potencializar seus esforços na formação inicial dos estudantes de EF para atuarem no setor saúde. O Manifesto recomenda às coordenações dos cursos de graduação em $\mathrm{EF}$ que os projetos político-pedagógicos sejam revistos de forma a garantir espaço para o campo da Saúde Coletiva e para o SUS, com disciplinas específicas, estágios supervisionados e disciplinas de eixos transversais. Sugere também a inclusão de atividades interdisciplinares e ações no ensino, na pesquisa e na extensão relacionadas ao campo da Saúde. Aos professores o referido documento sugere a reformulação e revisão dos planos de ensino de disciplinas direcionadas à saúde, para que incorporem 
conteúdos e aspectos da Saúde Coletiva. Além disso, acrescentam a necessidade de estimularem, quando possível, a inclusão da saúde como tema dos planos de ensino das disciplinas de diferentes enfoques.

Bagrichevsky (2007) defende que não basta apenas mudar a estrutura curricular para tornar viável uma nova 'porta de entrada' para o professor de Educação Física, mas esta mudança deve, sem dúvida, trazer aproximações preliminares com a realidade dos serviços de saúde. Bagrichevsky \& Estevão (2008) defendem ainda que, na formação do professor de EF, como preconizado pelo movimento da Promoção da Saúde, o conceito de saúde necessita ser ampliado a fim de que a área se desvincule do discurso reducionista, baseado na apologia do 'não ao sedentarismo', e passe a olhar a relação entre a atividade física e saúde através de um prisma multidimensional.

Outra iniciativa destacada pelo Manifesto da ABENEFS (2016), é a necessidade de investimento em programas específicos de formação voltados para a saúde. O documento afirma que aproximar os serviços de saúde e as IES ajuda a pensar e definir estratégias no campo da EF aplicáveis às necessidades do serviço público de saúde. Além disso, ressalta a importância de estimular a participação dos estudantes em disciplinas, grupos de estudo, projetos de extensão, pesquisa e iniciação científica voltada para a área de atividade física e saúde. Dialogando com as ideias de Freitas (2007) e Anjos \& Duarte (2009) percebemos a necessidade de estágios específicos para fortalecer a atuação na área da saúde. $\mathrm{O}$ estágio em saúde, quando bem orientado, pode preencher a lacuna da não integração ensino e trabalho, de modo a potencializar o cuidado integral e propiciar maior assimilação do campo de trabalho. O contato com a comunidade nos estágios consolida o proposto nas disciplinas que abordam os conhecimentos de Saúde Coletiva e Saúde Pública. Na medida em que tais conhecimentos vão sendo requisitados, o novo campo de atuação vai sendo reconhecido e efetivamente ocupado pelos alunos dos cursos de EF, colaborando também com a disseminação do conhecimento específico da EF dentro das equipes multiprofissionais e na sociedade. Em contrapartida a carência de disciplinas e estágios em Saúde Pública na grade curricular da graduação em Educação Física, tem feito com que muitos dos profissionais sintam-se incapazes de atuar na área e, por vezes, não reconheçam esse campo como de sua competência (Anjos \& Duarte, 2009).

Câmara, Gerez, Miranda \& Velardi (2010) acrescenta que o reconhecimento da Educação Física na área da saúde, perpassa pela necessidade de modificações na sua formação, de maneira a abandonar as amarras do tecnicismo e explorar o seu potencial educativo, no sentido da educação para a autonomia. Neste sentido, acreditamos que o fortalecimento da formação acontece na medida em que os alunos são incentivados a lidar, com autonomia crescente em sua formação, vivenciando situações críticas e contextos característicos ao processo de trabalho em saúde, estimulando, sobretudo, as práticas reflexivas (Carvalho \& Ceccim, 2006).

\section{CONSIDERAÇões}

No dia 11 de dezembro de 2015, em audiência pública, no Conselho Nacional de Educação (CNE), os conselheiros apresentaram uma proposta de minuta pelo fim do bacharelado, com revisão das diretrizes curriculares e proposta de aprovação da formação unificada na Licenciatura em Educação Física. Embora o debate sobre o tema não tenha terminado, nossas considerações vão ao encontro do que está sendo defendido pelo CNE. De acordo com Taffarel \& Santos Júnior (2015) o CNE defende que os cursos de formação profissional, não podem ser regidos por dúvidas e ingerência de conselhos profissionais que não formam profissionais, mas só regulam o exercício da profissão. Além disso, não podem existir restrições quanto a possibilidade de atuação em determinados campos de trabalho (a Constituição Federal e a LDB expressam isto). No entanto, Castellani Filho (2016) alerta que, no caso da unificação da formação, adotar uma postura dogmática, dificulta a percepção de que a mudança de realidade não depende disso. Concordando com o autor, defendemos que é preciso ir além da unificação da formação, mas pensar em diferentes estratégias que fortaleçam esta formação. 
Assim como muitos conselheiros do $\mathrm{CNE}$ e outros pesquisadores da área, acreditamos que o objeto tratado nas intervenções profissionais e nos estudos em EF, deve estar pautado na formação para a prática pedagógica, na ação docente, na organização do trabalho pedagógico em quaisquer espaços formativos. Independentemente se o contexto educativo é formal ou não formal; se é numa escola ou num posto de saúde; se é numa academia ou em um clube. O conhecimento de que trata a $\mathrm{EF}$ deve ser o mesmo em todos os campos de atuação: o movimento humano em toda a sua complexidade.

Estas reflexões nos dão subsídios para defender a formação única, ampliada e generalista, para os professores de EF. Os princípios norteadores da atuação da EF no SUS favorecem a participação dos egressos dos cursos de licenciatura 'plena' nas equipes multidisciplinares de saúde, quando elencam entre suas atribuições elementos que são exaustivamente difundidos na formação destes professores. Além disso, apontam, ine quivocamente, para a uma formação em EF, que contemple as abordagens presentes nas Ciências Naturais, em harmonia com as abordagens das Ciências Humanas. Não estamos negando a contribuição fundamental das Ciências Naturais no âmbito da Educação Física. O que buscamos, com fulcro nas Ciências Sociais, é trazer novos elementos para a discussão e ampliar a compreensão da relação entre educação física e saúde.

Desta forma, as ações da EF na área da saúde deverão ser construídas coletivamente com outros campos do conhecimento, visando um tratamento mais humano, baseado na escuta dos anseios e necessidades da sociedade, contribuindo com a melhoria na saúde do indivíduo, tornando-o mais crítico e autônomo.

\section{REFERÊNCIAS}

Associação Brasileira de Ensino da Educação Física para a Saúde (ABENEFS). (2016). Manifesto ABENEFS: Alinhando a formação inicial em Educação Física às necessidades do setor saúde. Disponível em https://www. abenefs.com. Acesso em 31/01/2018.

Alves Junior, E. D. (1992). As relações e os compromissos da Educação Física com a promoção da saúde. O idoso e a educação física informal em Niterói.

Anjos, T. C. D., \& Duarte, A. C. G. D. O. (2009). A Educação Física e a Estratégia de Saúde da Família: formação e atuação profissional. Physis: Revista de Saúde Coletiva, 19, 1127-1144.

Bagrichevsky, M. (2007). A formação profissional em educação física enseja perspectivas (críticas) para atuação na saúde coletiva. Educação Física e Saúde Coletiva: politicas de formação e perspectivas de intervenção. Porto Alegre: UFRGS, 33-45.

Bagrichevsky, M., \& Estevão, A. (2008). Perspectivas para a formação profissional em educação física: o SUS como horizonte de atuação. Arquivos em movimento, 4(1), 128-143.

Betti, M., Carvalho, Y. M. D., Daolio, J., e Pires, G. D. L. (2004). A avaliação da educação física em debate: implicações para a subárea pedagógica e sociocultural. Revista Brasileira de Pós-Graduação, 1(2).

Betti, M. (2005). Sobre teoria e prática: manifesto pela redescoberta da educação física. Revista Digital. Buenos Aires, 90.

Bracht, V. (2000). Educação física \& ciência: cenas de um casamento (in) feliz. Revista brasileira de ciências do esporte, $22(1)$.

Brasil. Ministério da Educação. (2004). Parecer CNE/CES no 58 de 18 de fevereiro de 2004. Diretrizes Curriculares Nacionais para os cursos de graduação em Educação Física. Diário Oficial da União.

Brasil. Ministério da Educação. (2011). Parecer CNE/CES no 274/2011 de 6 de julho 2011 da Câmara de Educação Superior do Conselho Nacional de Educação. Diário Oficial da União.

Brasil. Ministério da Saúde. (1998). Resolução do Conselho Nacional de Saúde, n. 287. Diário Oficial da União.

Brasil. Ministério da Saúde. Secretaria Executiva. (2001). SUS-princípios e conquistas.

Brasil. Ministério da Saúde. (2005). Pró-saúde: programa nacional de reorientação da formação profissional em saúde.

Brasil. Ministério da Saúde. (2006). Política Nacional de Promoção da Saúde. Secretaria de Vigilância em Saúde. Série B. Textos Básicos de Saúde. Série Pactos pela Saúde. 
Brasil. Ministério da Saúde. (2007). Programa Nacional de Reorientação da Formação Profissional em Saúde-PróSaúde: objetivos, implementação e desenvolvimento potencial. Série C.

Brasil. Ministério da Saúde. (2008). Portaria no 154 de 24 de janeiro de 2008, cria os Núcleos de Apoio à Saúde da Família - NASF. Diário Oficial da União.

Brasil. (2009). Ministério da Saúde. Secretaria de Atenção Básica. Departamento de Atenção Básica. Diretrizes do NASF: Núcleo de Apoio à Saúde da Família.

Brasil. (2012). Portaria n 3.124, de 28 de dezembro de 2012. Redefine os parâmetros de vinculação dos Núcleos de Apoio à Saúde da Família (NASF) Modalidades 1 e 2 às Equipes Saúde da Família e/ou Equipes de Atenção Básica para populações específicas, cria a Modalidade NASF 3, e dá outras providências. Diário Oficial da União.

Brugnerotto, F., \& Simões, R. (2009). Caracterização dos currículos de formação profissional em Educação Física: um enfoque sobre saúde. Physis: Revista de Saúde Coletiva, 19, 149-172.

Caparroz, F. E., \& Bracht, V. (2007). O tempo e o lugar de uma didática da educação física. Revista Brasileira de Ciências do Esporte, 28(2), 21-37.

Carmo Júnior, W. (1998). Educação Física e a ciência, qual ciência?. Motriz. Journal of Physical Education. UNESP, 44-51.

Carvalho, Y. M. D., \& Ceccim, R. B. (2006). Formação e educação em saúde: aprendizados com a saúde coletiva. In Tratado de saúde coletiva, p. 149-182.

Castellani Filho, L. (2016). A Formação sitiada. Diretrizes Curriculares de Educação Física em disputa: jogo jogado?. Pensar a Prática, 19(4).

Cellard, A. (2008). A análise documental. POUPART, J. et al. A pesquisa qualitativa: enfoques epistemológicos e metodológicos. Petrópolis, Vozes, 295, p. 2010-2013.

Conte, M. \& Gonçalves, A. (2001). Dimensões controversas da interação Saúde Coletiva/Atividade Física. In: Congresso Brasileiro de Ciências do Esporte, 2001, Caxambu, MG. Sociedade, ciência e ética: desafios para a educação fisicalciências do esporte. Anais. Campinas: CBCE.

Falci, D.M. e Belisário, S. A. (2013). A inserção do profissional de educação física na atenção primária à saúde e os desafios em sua formação. Interface-Comunicação, Saúde, Educação, 17(47).

Faria, B.A., Bracht, V., e Machado, T.S. (2010). Inovação pedagógica na educação física: o que aprender com práticas bem sucedidas?. Ágora para la Educación Física y el Deporte, 12(1), 11-28.

Faria Junior, A. G. (2001). Reflexões sobre a educação física brasileira-a carta de Belo Horizonte. Revista Brasileira de Ciências do Esporte, 23(1).

Ferreira, M. S. (2001). Aptidão física e saúde na educação física escolar: ampliando o enfoque. Revista brasileira de ciências do esporte, 22(2).

Fontoura, H. D. (2011). Tematização como proposta de análise de dados na pesquisa qualitativa. Formação de professores e diversidades culturais: múltiplos olhares em pesquisa. Niterói: Intertexto, pp. 61-82.

Freire, E.S., Verenguer, R.C.G. e Reis, M.C.C. (2002) Educação Física: pensando a profissão e a preparação profissional. Revista Mackenzie de Educą̧ão Física e Esporte, 1(1), 39-46.

Freitas, F. F. (2007) A Educação Física no serviço público de saúde. São Paulo: Hucitec.

Gonçalves, A., \& Castro, G. C. (2009). Intervenção e formação em Educação Física com destaque à Saúde. Motriz. Journal of Physical Education. UNESP, 374-382.

Gonzaga, A. M. (2006). A pesquisa em educação: um desenho metodológico centrado na abordagem qualitativa. Pesquisa em educação: alternativas investigativas com objetos complexos. São Paulo: Loyola, pp. 65-92.

Hallal, P. C., \& Knuth, A. G. (2011). Epidemiologia da atividade física e a aproximação necessária com as pesquisas qualitativas. Revista Brasileira de Ciências do Esporte, 33(1), 181-192.

Luz, M. T. (2007). Educação física e saúde coletiva: papel estratégico da área e possibilidades quanto ao ensino na graduação e integração na rede de serviços públicos de saúde. Fraga, Alex e Wachs, Felipe. Educação Física e saúde coletiva: políticas de formação e perspectivas de intervenção. Porto Alegre: Editora UFRGS. 
Manoel, E.J., y Carvalho, Y. M. (2011). Pós-graduação na educação física brasileira: a atração (fatal) para a biodinâmica. Educação e Pesquisa, 37(2), 389-406.

Moretti, A. C., Almeida, V., Westphal, M. F., \& Bógus, C. M. (2009). Práticas corporais/atividade física e políticas públicas de promoção da saúde. Saúde e Sociedade, 18, 346-354.

Nunes, M. P., Votre, S. J., \& Santos, W. D. (2012). O profissional em Educação Física no Brasil: desafios e perspectivas no mundo do trabalho. Motriz, 18(2), 280-90.

Oliveira, A. A. P. D. (2007). Análise documental do processo de capacitação dos multiplicadores do projeto nossas crianças: Janelas de oportunidades no município de São Paulo à luz da Promoção da Saúde (Doctoral tesis) Universidade de São Paulo, Brasil.

Oliveira, V. J. M., Gomes, I. M. \& Bracht, V. (2015) Educação para a saúde na educação física escolar: uma questão pedagógica!. Cadernos de formação RBCE, v. 5, n. 2. Disponível em: http://revista.cbce.org.br/index.php/cader nos/article/view/2068/1022. Acesso em: 03 out. 2017.

Ouriques, J.C. (2006). Análise de documentos internacionais de promoção da saúde: possiveis contribuiçöes para a Educação Fisica brasileira. (Master dissertation em Educação Física, Universidade Federal de Santa Catarina, Santa Catarina).

Pasquim, H.M. (2010). A Saúde Coletiva nos cursos de graduação em Educação Física. Saúde e Sociedade, 19(1), 193-200.

Pimentel, A. (2001). O método da análise documental: seu uso numa pesquisa historiográfica. Cadernos de pesquisa, (114), 179-195.

Rossoni, E., \& Lampert, J. (2004). Formação de profissionais para o Sistema Único de Saúde e as diretrizes curriculares. Boletim da Saúde, 18(1), 87-98.

Scabar, T. G., Pelicioni, A. F., \& Pelicioni, M. C. F. (2012). Atuação do profissional de Educação Física no Sistema Único de Saúde: uma análise a partir da Política Nacional de Promoção da Saúde e das Diretrizes do Núcleo de Apoio à Saúde da Família-NASF. J Health Sci Inst, 30(4), 411-418.

Silva, J. F., Golin, C. H., Neto, J. B., Pereira, L. A., Asano, R. Y., \& Silva, J. C. (2013). As academias de musculação como espaços educativos não formais. Educação Física em Revista, 7(2), 3-17.

Sobral, F. (1991). Investigação das relações entre saúde e desporto: história, estado actual e perspectivas de evolução. Actas-Desporto. Saúde. Bem-Estar-Jornadas Cientificas, FCDEF-Universidade do Porto.

Souza, S.C. \& Loch, M.R (2011). Intervenção do profissional de Educação Física nos Núcleos de Apoio à Saúde da Família em municípios do norte do Paraná. Rev. Bras. Ativ. Fis. Saúde,16(1), 5-10.

Taffarel, C. N. Z., \& Santos Júnior, C. L. (2015). Desafios para a educação física/ciência do esporte: a necessidade de uma nova síntese. Produção do conhecimento na educação física: balanços, debates e perspectivas. Maceió: Edufal, pp. 166-207.

Velozo, E.L. (2010). Educação Física, Ciência e Cultura. Rev. Bras. Cienc. Esporte, 31(3), 79-93.

Zimmermann, A.C. (2001). Reflexões sobre a relação saúde e atividade física/qualidade de vida. In: Congresso Brasileiro de Ciências do Esporte, Caxambu, MG. Sociedade, ciência e ética: desafiospara a educação física/ciências do esporte. Anais. Campinas: CBCE. 